\title{
The interaction of new oxicam derivatives with lipid bilayers as measured by calorimetry and fluorescence spectroscopy
}

\author{
Jadwiga Maniewska1凶, Justyna Gąsiorowska², Berenika Szczęśniak-Sięga1凶 \\ and Krystyna Michalak² \\ 1Department of Chemistry of Drugs, Wroclaw Medical University, Wrocław, Poland; 2Department of Biophysics, Wroclaw Medical University, \\ Wrocław, Poland
}

The purpose of the present work was to assess the ability of five new oxicam analogues to interact with the lipid bilayers. To characterize the interaction of newly synthesized NSAIDs (non-steroidal anti-inflammatory drugs) analogues with DPPC lipid bilayers the two following techniques were applied - differential scanning calorimetry (DSC) and fluorescence spectroscopy. The results obtained by these experimental approaches show that new oxicams analogues interact with the lipid model membranes under consideration. As demonstrated both in calorimetric and spectroscopic studies, the greatest influence on the thermotropic properties of the lipid membrane and on the quenching of fluorescence of Laurdan and Prodan was exerted by a derivative named PR47 containing in its structure a two-carbon aliphatic linker with a carbonyl group, as well as bromine and trifluoromethyl substituents.

Key words: oxicam derivatives, NSAIDs analogues, piroxicam, 1,2benzothiazine derivatives synthesis, model lipid bilayers, differential scanning calorimetry (DSC), fluorescence spectroscopy

Received: 02 February, 2018; revised: 13 April, 2018; accepted: 17 April, 2018; available on-line: 22 May, 2018

e-mails: jadwiga.maniewska@umed.wroc.pl (JM); berenika.szczesniak-siega@umed.wroc.pl (BSS)

Abbreviations: NSAIDs, non-steroidal anti-inflammatory drugs; DSC, differential scanning calorimetry; COX, cyclooxygenase; ER, endoplasmic reticulum

\section{INTRODUCTION}

Oxicams (e.g. piroxicam, meloxicam, Fig. 1), which are known as a class of non-steroidal anti-inflammatory drugs (NSAIDs) are mainly used in the treatment of inflammation and pain which occur during chronic rheumatic diseases. Enriched with an enolic moiety they are 1,2-benzothiazine derivatives (Xu et al., 2014).

The molecular basis of NSAIDs mechanism of action is the ability of these drugs to inhibit cyclooxygenase $(\mathrm{COX})$, occurring in the form of two isoforms, COX1 and COX-2. COX enzymes are membrane-bound, luminal surface of endoplasmic reticulum (ER) resident, glycoproteins, which catalyze the conversion of arachidonic acid to prostaglandins, acting as second messengers for immune processes and stimulating malignancies (Mbonye et al., 2006; Dixon et al., 2013). Moreover, COX-2 protein is involved in activation of carcinogens, tumor initiation and promotion, as well as inhibition of apoptosis together with promotion of angiogenesis and metastasis (Ghosh et al., 2010). Increased expression of the COX-2 protein, which is the target of NSAIDs, has been widely reported in pathogenesis mostly of solid tu- mors, and for this reason these drugs are evaluated also as cancer preventive compounds (de Groot et al., 2007; Park et al., 2017). Furthermore, Lenard Lichtenberger et al. have proposed that one of the alternative mechanism by which NSAIDs may induce differential biological effects and exert a toxic influence is their interaction with components of cellular membranes and in consequence an alteration of membrane biophysical properties (Lichtenberger et al., 2012). The chemopreventive activity of NSAIDs might be at least partially related to their ability to interact with the lipid phase of biological membranes. In order to achieve the main cellular target of NSAIDs which is COX enzyme associated with ER membrane, these compounds have to pass through the biological membranes first. That is why many efforts are being made for better understanding of NSAIDs interaction with biological membranes (Nunes et al., 2011). Pharmacological actions of different drugs (among them NSAIDs) may be a consequence of their direct interaction with proteins, as well as with lipid phase of membranes. Changes induced in lipid phase, such as an alteration of membrane curvature and phase behavior may in consequence indirectly modify a conformation of membrane proteins. For that reason the investigation of drug-membrane interactions is essential for understanding of drugs' pharmacokinetics and molecular mechanisms of their action. This knowledge is crucial for designing new drug structures (Lucio et al., 2010; Peetla et al., 2009; Seddon et al., 2009). Peetla et al. have indicated that biophysical changes in membrane phospholipids observed in multidrug resistant cancer cells affect the transport and delivery of anticancer drugs (Peetla et al., 2013). On the other hand, Chakraborty et al. have demonstrated that permeabilization of the mitochondrial membrane induced by piroxicam may promote apoptosis (Chakraborty et al., 2007). The results of these studies indicate that an alteration of biophysical membrane properties in the presence of NSAIDs may be important for putative anticancer activity of these drugs (Pereira-Leite et al., 2013).

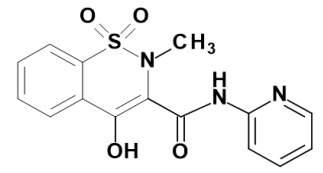

piroxicam

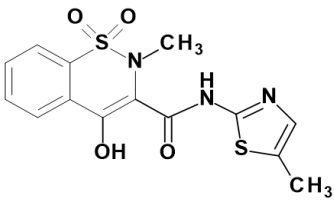

meloxicam
Figure 1. Chemical structures of typical oxicams 
An understanding of the relationship between biophysical properties of cell membrane and drug delivery processes or modulation of drug-resistance mechanisms may be crucial for developing new strategies to overcome the multidrug resistance (MDR) of cancer cells.

Unfortunately, the chronic usage of nonselective COX inhibitors is burdened with a risk of gastrointestinal side-effects, such as ulceration and bleeding, while usage of COX-2 selective inhibitors may cause adverse cardiovascular effects as myocardial infraction (Rizzo, 2011; Wang \& Dubois, 2010). Therefore, we designed and synthesized new oxicam derivatives as potential multitarget drugs which would be an analgesic and at the same time anti-inflammatory and chemopreventive drugs in cancer. Preliminary experiments on the few newly synthesized oxicams derivatives carried out in our laboratory revealed that these compounds reduce the level of the expression of $\mathrm{COX}-2, \mathrm{Bcl}-2$ proteins and ABCB1 multidrug transporter in the human colorectal adenocarcinoma cell line LoVo (Środa-Pomianek et al., 2015). The purpose of the present work was to assess the ability of five new oxicam analogues to interact with lipid bilayers used as simple model of cell membranes. For comparison, the piroxicam, well known NSAID was also used in the experiments.

\section{MATERIALS AND METHODS}

Chemicals. 1,2-dipalmitoyl-n-glycero-3-phosphatidylcholine (DPPC) was purchased from Sigma-Aldrich
(Poznań, Poland). The lipid was used as delivered without further purification.

Fluorescent labels: 6-dodecanoyl-2-dimethylaminonaphthalene (Laurdan) and 6-propionyl-2-dimethylaminonaphthalene (Prodan) were purchased from Molecular Probes (USA).

Tris-EDTA buffer solution ( $\mathrm{pH}$ 7.4) was purchased from Sigma-Aldrich.

Fluorescence probes: 6-dodecanoyl-2-dimethylaminonaphthalene (Laurdan) and 6-propionyl-2-dimethylaminonaphthalene (Prodan) were purchased from Molecular Probes (USA). Laurdan and Prodan were dissolved in DMSO to obtain $1 \mathrm{mM}$ stock solutions.

Since studied oxicams derivatives were insoluble in water their chloroform or DMSO solutions were used for experiments. All other chemicals used in this study were of analytical grade.

\section{Synthesis}

General procedure for the preparation of compounds PR14, PR44, PR45, PR47 and PR48 (Scheme 1). The proton nuclear magnetic resonance ( ${ }^{1} \mathrm{H}$ NMR) spectra of synthetized compounds were measured by Bruker $300 \mathrm{MHz}$ NMR spectrometer using $\mathrm{CDCl}_{3}$ as solvent and TMS as an internal standard. Spin multiplicities are given as s (singlet), brs (broad singlet), $\mathrm{d}$ (doublet), t (triplet) and $\mathrm{m}$ (multiplet). Infrared spectra $\left(\mathrm{cm}^{-1}\right)$ were recorded on a Perkin-Elmer Spectrum Two UATR FT-IR spectrometer. The samples were applied as neat solids. Melting points were determined in open
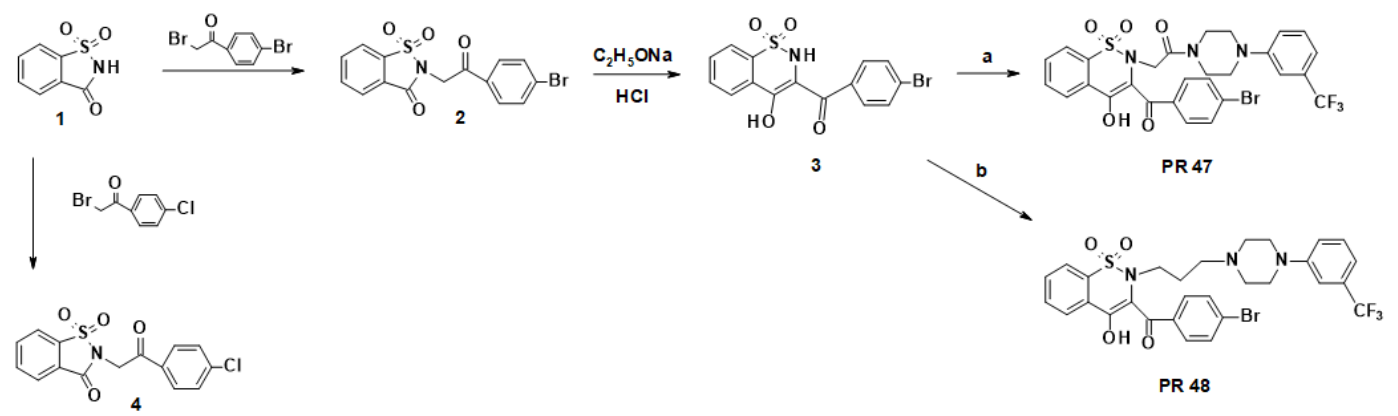

$\mid \mathrm{C}_{2} \mathrm{H}_{5} \mathrm{ONa} / \mathrm{HCl}$
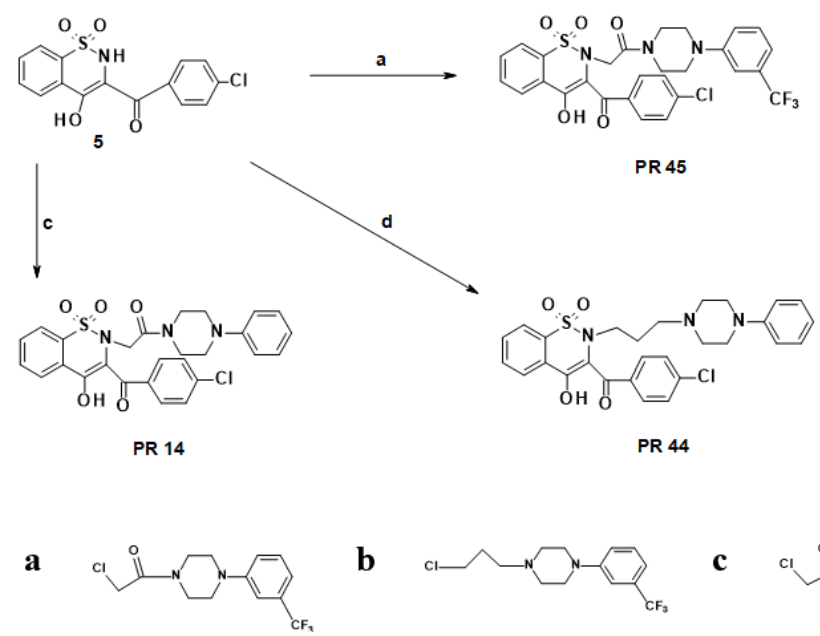

c

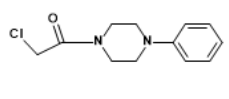

d

Scheme 1. Synthesis of new oxicams derivatives - PR14, PR44, PR45, PR47 and PR48. 
capillary tubes and were uncorrected. Elemental analyses were performed by Carlo Erba NA 1500 analyzer and were within $\pm 0.4 \%$ of the theoretical value. Reactions were monitored by thin layer chromatography (TLC) on silica gel plates (Merck 60 F254), visualized with ultraviolet light. Flash chromatography was performed on silica gel column (230-400 mesh) using ethyl acetate.

Synthesis and experimental data of compounds 2 5 (Scheme 1) was previously reported; for 2 and 3 (Krzyżak et al., 2013), for 4 and 5 (Maniewska et al., 2014).

3-(4-chlorobenzoyl)-4-bydroxy-2-[2-(4-phenyl-1-piperazinyl)-2-oxoetbyl]-2H-1,2-benzothiazine 1,1-dioxide (PR 14). A mixture of $\mathbf{5}$ (3 mmol, $1.00 \mathrm{~g})$ and 1-(2-chloro-1-oxoethyl)-4-phenylpiperazine $c$ (3 mmol, $0.72 \mathrm{~g})$ with EtONa $(3 \mathrm{ml}, 2.3 \%)$ in $20 \mathrm{ml}$ of anhydrous EtOH was stirred at $70^{\circ} \mathrm{C}$ under reflux for $8 \mathrm{~h}$. After cooling to room temperature ethanol was distilled off in vacuo. The residue was dissolved in $\mathrm{CHCl}_{3}(50 \mathrm{ml})$ and filtered. The filtrate was concentrated in vacuo and the residue was purified by crystallisation from ethanol $(50 \mathrm{ml})$ to give PR 14 as yellow crystals with $41 \%$ yield.

Anal. $\mathrm{C}_{27} \mathrm{H}_{24} \mathrm{ClN}_{3} \mathrm{O}_{5} \mathrm{~S}$ (m.w. 538.01); mp $182-183^{\circ} \mathrm{C}$ (EtOH). ${ }^{1} \mathrm{H}$ NMR $\left(300 \mathrm{MHz}, \mathrm{CDCl}_{3}\right) \delta(\mathrm{ppm}): 2.61-4.20$ $\left(\mathrm{m}, 10 \mathrm{H}, \mathrm{H}_{\text {piperazine }}\right.$ and $\left.\mathrm{CH}_{2} \mathrm{CO}\right), 6.81-8.26(\mathrm{~m}, 13 \mathrm{H}, \mathrm{ArH})$, 15.47 (s, 1 $\left.\mathrm{H}_{\text {inera }} \mathrm{OH}_{\text {enolic }}\right)$. FT-IR $\left(\mathrm{cm}^{-1}\right): 1668,1592$ (CO), 1335, $1170\left(\mathrm{SO}_{2}\right) ;$ Anal. Calcd: C, 60.28; H, 4.50; N, 7.81. Found: C, 60.38; H, 4.61; N, 7.64.

3-(4-chlorobenzoyl)-4-bydroxy-2-[3-(4-phenyl-1-piperazinyl)propyl]-2H-1,2-benzothiazine 1,1-dioxide (PR44). A mixture of 5 (3 mmol, $1.00 \mathrm{~g}$ ) and 1-(3-chloropropyl)-4-phenylpiperazine d (3 mmol, $0.72 \mathrm{~g})$ with EtONa $(3 \mathrm{ml}, 2.3 \%)$ in $20 \mathrm{ml}$ of anhydrous EtOH was stirred at $70^{\circ} \mathrm{C}$ under reflux for $8 \mathrm{~h}$. The rest of the procedure was similar to that used for PR 14 except crystallisation from toluene. Compound PR 44 was obtained as yellow powder with $16 \%$ yield.

Anal. $\mathrm{C}_{28} \mathrm{H}_{28} \mathrm{ClN}_{3} \mathrm{O}_{4} \mathrm{~S}$ (m.w. 538.06); mp $134-136^{\circ} \mathrm{C}$ (toluene). ${ }^{1} \mathrm{H}$ NMR $\left(300 \mathrm{MHz}, \mathrm{CDCl}_{3}\right) \delta$ (ppm): 1.30 (brs, $2 \mathrm{H}, \mathrm{CH}_{2} \mathrm{CH}_{2} \mathrm{CH}_{2}$ ), 2.01 (brs, $2 \mathrm{H}, \mathrm{CH}_{2} \mathrm{CH}_{2} \mathrm{CH}_{2}$ ), 2.29-2.35 (m, 4H, $\left.\mathrm{H}_{\text {piperazine }}\right), 3.07-3.45\left(\mathrm{~m}, 6 \mathrm{H}, \mathrm{H}_{\text {piperazine }}\right.$ and $\left.\mathrm{CH}_{2} \mathrm{CH}_{2} \mathrm{CH}_{2}\right), 6.85-8.17(\mathrm{~m}, 13 \mathrm{H}, \mathrm{ArH}), 15.71(\mathrm{~s}$, $\left.1 \mathrm{H}, \mathrm{OH}_{\text {enolic }}\right)$. FT-IR $\left(\mathrm{cm}^{-1}\right): 1605(\mathrm{CO}), 1325,1175\left(\mathrm{SO}_{2}\right)$; Anal. Calcd: C, 62.50; H, 5.25; N, 7.81. Found: C, 62.35; H, 5.22; N, 7.67.

3-(4-chlorobenzoyl)-4-bydroxy-2-[2-(3-trifluoromethylphenyl)-1-piperazinyl)-2-oxoethyl]-2H-1,2-benzothiazine 1,1-dioxide (PR 45). A mixture of 5 (3 mmol, $1.00 \mathrm{~g})$ and 1-(2-chloro-1-oxoethyl)-4-(3-trifluoromethylphenyl)-piperazine a $(3 \mathrm{mmol}, 0.91 \mathrm{~g})$ with $\operatorname{EtONa}(3 \mathrm{ml}, 2.3 \%)$ in $20 \mathrm{ml}$ of anhydrous $\mathrm{EtOH}$ was stirred at $70^{\circ} \mathrm{C}$ under reflux for $8 \mathrm{~h}$. The rest of the procedure was similar to that used for PR14. Compound PR45 was obtained as yellow powder with $39 \%$ yield.

Anal. $\mathrm{C}_{28} \mathrm{H}_{23} \mathrm{ClF}_{3} \mathrm{~N}_{3} \mathrm{O}_{5} \mathrm{~S}$ (m.w. 606.01); mp $125-130^{\circ} \mathrm{C}$ (EtOH). ${ }^{1} \mathrm{H}$ NMR $\left(300 \mathrm{MHz}, \mathrm{CDCl}_{3}\right) \delta(\mathrm{ppm}): 2.07$ (brs, $\left.2 \mathrm{H}, \mathrm{CH}_{2} \mathrm{CO}\right), 2.93-3.28$ ( $\left.\mathrm{m}, 8 \mathrm{H}, \mathrm{H}_{\text {piterasine }}\right), 6.93-8.23$ (m, $12 \mathrm{H}, \mathrm{ArH}), 15.55\left(\mathrm{~s}, 1 \mathrm{H}, \mathrm{OH}_{\text {enolic }}\right)$. Piperazine $\mathrm{F}$-IR $\left(\mathrm{cm}^{-1}\right): 1668$, 1593 (CO), 1332, $1170\left(\mathrm{SO}_{2}\right)$; Anal. Calcd: C, 55.49; H, 3.83; N, 6.93. Found: C, 55.55; H, 3.93; N, 6.73.

3-(4-bromobenzoyl)-4-bydroxy-2-[2-(3-trifluoromethylphenyl)-1-piperazinyl)-2-oxoethyl]-2H-1,2-benzothiazine 1,1-dioxide (PR 47). A mixture of 3 (3 mmol, $1.14 \mathrm{~g})$ and 1-(2-chloro-1-oxoethyl)-4-(3-trifluoromethylphenyl)-piperazine a $(3 \mathrm{mmol}, 0.91 \mathrm{~g})$ with $\mathrm{EtONa}(3 \mathrm{ml}, 2.3 \%)$ in 20 $\mathrm{ml}$ of anhydrous EtOH was stirred at $70^{\circ} \mathrm{C}$ under reflux for $8 \mathrm{~h}$. The rest of the procedure was similar to that used for PR14. Compound PR47 was obtained as yellow crystals with $16 \%$ yield.
Anal. $\mathrm{C}_{28} \mathrm{H}_{23} \mathrm{BrF}_{3} \mathrm{~N}_{3} \mathrm{O}_{5} \mathrm{~S}$ (m.w. 650.46); mp $139-140^{\circ} \mathrm{C}$ (EtOH). ${ }^{1} \mathrm{H}$ NMR $\left(300 \mathrm{MHz}, \mathrm{CDCl}_{3}\right) \delta$ (ppm): 2.98-3.70 $\left(\mathrm{m}, 10 \mathrm{H}, \mathrm{CH}_{2} \mathrm{CO}\right.$ and $\left.\mathrm{H}_{\text {piperazine }}\right), 6.97-8.27(\mathrm{~m}, 12 \mathrm{H}, \mathrm{ArH})$, 15.47 (s, $1 \mathrm{H}, \mathrm{OH}_{\text {enolic }}$ ). FT-IR $\left(\mathrm{cm}^{-1}\right): 1664,1587$ (CO), 1342, $1177\left(\mathrm{SO}_{2}\right)$. Anal. Calcd: C, 51.70; H, 3.56; N, 6.46. Found: C, 51.34; H, 3.27; N, 6.28.

3-(4-bromobenzoyl)-4-bydroxy-2-\{3-[4-(3-trifluoromethylphenyl)-1-piperazinyl]propyl $\}$-2H-1,2-benzothiazine 1,1-dioxide (PR48). A mixture of 3 (3 mmol, $1.14 \mathrm{~g})$ and 1-(3-chloropropyl)-4-(3-trifluoromethylphenyl)-piperazine $b \quad$ (3 mmol, $0.92 \mathrm{~g})$ with EtONa $(3 \mathrm{ml}, 2.3 \%)$ in $20 \mathrm{ml}$ of anhydrous EtOH was stirred at $70^{\circ} \mathrm{C}$ under reflux for $8 \mathrm{~h}$. The rest of the procedure was similar to that used for PR14. Compound PR48 was obtained as yellow powder with $45 \%$ yield.

Anal. $\mathrm{C}_{29} \mathrm{H}_{27} \mathrm{BrF}_{3} \mathrm{~N}_{3} \mathrm{O}_{4} \mathrm{~S}$ (m.w. 650.51); mp $77-79^{\circ} \mathrm{C}$ (EtOH). ${ }^{1} \mathrm{H}$ NMR $\left(300 \mathrm{MHz}, \mathrm{CDCl}_{3}\right) \delta$ (ppm): 1.26 (brs, $2 \mathrm{H}, \mathrm{CH}_{2} \mathrm{CH}_{2} \mathrm{CH}_{2}$ ), 2.04 (brs, $2 \mathrm{H}, \mathrm{CH}_{2} \mathrm{CH}_{2} \mathrm{CH}_{2}$ ), 2.37 (brs, $\left.4 \mathrm{H}, \mathrm{H}_{\text {piperazine }}\right), 3.19-3.45\left(\mathrm{~m}, 6 \mathrm{H}, \mathrm{H}_{\text {piperazine }}\right.$ and $\left.\mathrm{CH}_{2} \mathrm{CH}_{2} \mathrm{CH}_{2}\right), 7.03-8.19(\mathrm{~m}, 12 \mathrm{H}, \mathrm{ArH}), 15.47^{\text {piperazine }}(\mathrm{s}, 1 \mathrm{H}$, $\left.\mathrm{OH}_{\text {enolic }}\right)$. FT-IR $\left(\mathrm{cm}^{-1}\right)$ : 1606 (CO), 1330, $1177\left(\mathrm{SO}_{2}\right)$. Anal. Calcd: C, 53.54; H, 4.18; N, 6.46. Found: C, 53.51; H, 4.26; N, 6.45 .

\section{Differential scanning calorimetry}

For each calorimetric sample $2 \mathrm{mg}$ of DPPC was dissolved in the appropriate amount of chloroform stock solution $(5 \mathrm{mM})$ of the investigated oxicam derivative. The oxicam/phospholipid molar ratios in the samples were: $0.06,0.08,0.10,0.12$. Than the phospholipid was transferred onto the dry film - the solvent was evaporated under a stream of nitrogen and the residual solvent was evacuated under vacuum for $2 \mathrm{~h}$. Samples were hydrated by $20 \mu$ l of Tris-EDTA buffer ( $\mathrm{pH}$ 7.4). Hydrated mixtures were heated to the temperature higher by $10^{\circ} \mathrm{C}$ than the main phase transition temperature of DPPC and vortexed until homogeneous dispersion was obtained. After that the samples were transferred into aluminium sample pans type Concavus (Netsch) and sealed. Thermal measurements were performed using a differential scanning calorimeter DSC 214 Polyma (Netzsch). The samples were scanned at a rate of $1^{\circ} \mathrm{C} / \mathrm{min}$. Data were analyzed off-line using Netzsch software. The transition enthalpies are stated in $[\mathrm{J} / \mathrm{g}]$ and the measured heat was normalized per gram of lipid.

\section{Fluorescence spectroscopy}

Small unilamellar liposomes formed from DPPC were obtained by sonication of $2 \mathrm{mM}$ lipid suspension in $20 \mathrm{mM}$ Tris- $\mathrm{HCl}$ buffer $(150 \mathrm{mM} \mathrm{NaCl}, 0.5 \mathrm{mM}$ EDTA, pH 7.4) using UP 200s sonicator (Dr Hilscher, Berlin, Germany). The stock solutions of the studied oxicams derivatives $(30 \mathrm{mM})$ were prepared in DMSO. Liposomes were incubated with $5 \mu \mathrm{M}$ of fluorescent probe (Laurdan or Prodan) in darkness for $30 \mathrm{~min}$ at room temperature. Then the studied compound was added and the liposomes were incubated for another 20 min (in darkness at room temperature). The oxicam derivatives concentrations were within the range 25-125 $\mu \mathrm{M}$.

The fluorescence experiments were carried out with LS $50 B$ spectrofluorimeter (Perkin-Elmer Ltd.) equipped with a xenon lamp using emission and excitation slits of $5 \mathrm{~nm}$. The excitation wavelength for Laurdan was 390 $\mathrm{nm}$ and for Prodan - $360 \mathrm{~nm}$. The recorded fluorescence spectra were processed with FLDM Perkin-Elmer 

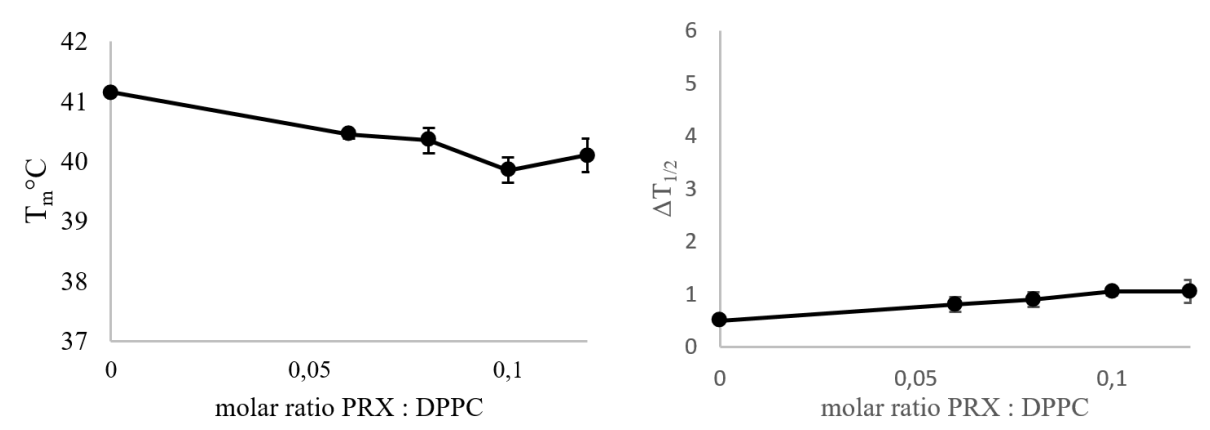

Figure 2. Influence of piroxicam (PRX, $\bullet$ ) on the DPPC main phase transition temperature $\left(T_{\mathrm{m}}\right)$ and peak half-height width $(\Delta T 1 / 2)$. Bars represent standard deviations of eight measurements, where no error bars are shown, they were smaller than the symbols representing results.

2000 software. The measurements were conducted at room temperature $\left(25^{\circ} \mathrm{C}\right)$.

\section{RESULTS}

The evaluation of NSAIDs-membrane interactions has to date been the subject of numerous studies by its in vitro simulation using a wide range of experimental techniques. The thermal effects of four oxicams (meloxicam, tenoxicam, piroxicam and lornoxicam) in model lipid membranes have been studied in DPPC bilayers by Kyriokou and coworkers (Kyriokou et al., 2004). The NSAIDs investigated there caused the lowering of the main phase transition temperature together with the abolition of DPPC pretransition. Fluorescence quenching as an experimental technique has also been employed previously to characterize the interaction of NSAIDs (eg. indomethacin) with lipid bilayers (Zhou et al., 2010).

\section{Differential scanning calorimetry}

Differential scanning calorimetry (DSC) is a relatively fast and inexpensive research method showing how the studied additives modify the phase transition profile of lipid (Jain \& Wu, 1977). In our research we use DSC as a preliminary technique to investigate the interaction of the newly synthesized compounds with model membranes.

We investigated the influence of five new compounds (PR14, PR44, PR45, PR47, PR48 - see Scheme 1) on thermal properties of DPPC bilayers in $\mathrm{pH} 7.4$ (TrisEDTA buffer). For comparison the effect of piroxicam, a well-known NSAID was recorded as well. Thermotropic properties of DPPC bilayers in the presence of oxicam derivatives in water and in acidic buffer have been previously studied by Kyrikou and coworkers. They studied the thermal effects of four oxicams in DPPC multibilayers (Kyrikou et al., 2004). They found that piroxicam caused broadening of the main phase transition $\left(\Delta T_{1 / 2}\right)$ of DPPC bilayers and lowering of the main phase transition temperature $\left(T_{\mathrm{m}}\right)$. Similar results were obtained in our studies (Fig. 2).

The impact of the studied compounds on the lipid thermal behavior is presented in Fig. 3, showing the example thermograms of DPPC mixed with piroxicam (PRX), PR47 and PR44 at different molar ratios. The addition of the studied compounds caused the disappearance of the DPPC pretransition and concentration-dependant shift of the main transition temperature towards lower values, accompanied by a decrease in the transition peaks area and the broadening of the peaks.

Additionally, at PR47:DPPC molar ratios of $0.08,0.10$ and 0.12 the main peak appeared to be composed of two overlapping peaks and characterized by a shoulder on this peak shifted towards higher temperature. This means that phase transition is less cooperative.

The dependencies of the main transition temperature $\left(T_{\mathrm{m}}\right)$, transition half-height width $\left(\Delta T_{1 / 2}\right)$ and the transition enthalpy $(\Delta \mathrm{H})$ on the oxicam derivative:lipid molar ratio obtained for the mixtures of DPPC with PR14,

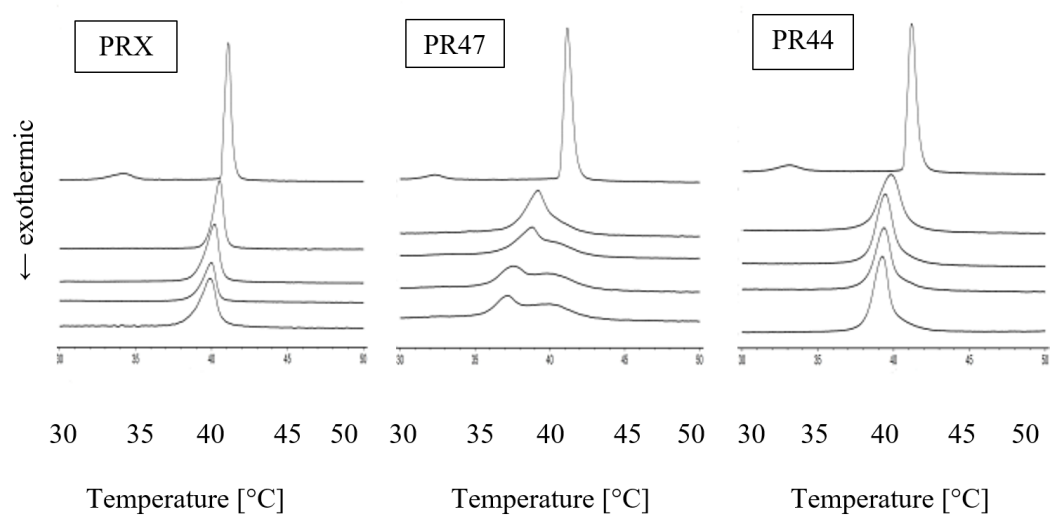

Figure 3. The example thermograms obtained for DPPC mixed with piroxicam (PRX), compound PR47 or PR44 as well as pure lipid (the first curve from the top).

Curves in the Figure represent the thermograms obtained for different studied compound:DPPC molar ratios (from the bottom: 0.12 , $0.10,0.08,0.06$, pure lipid). 

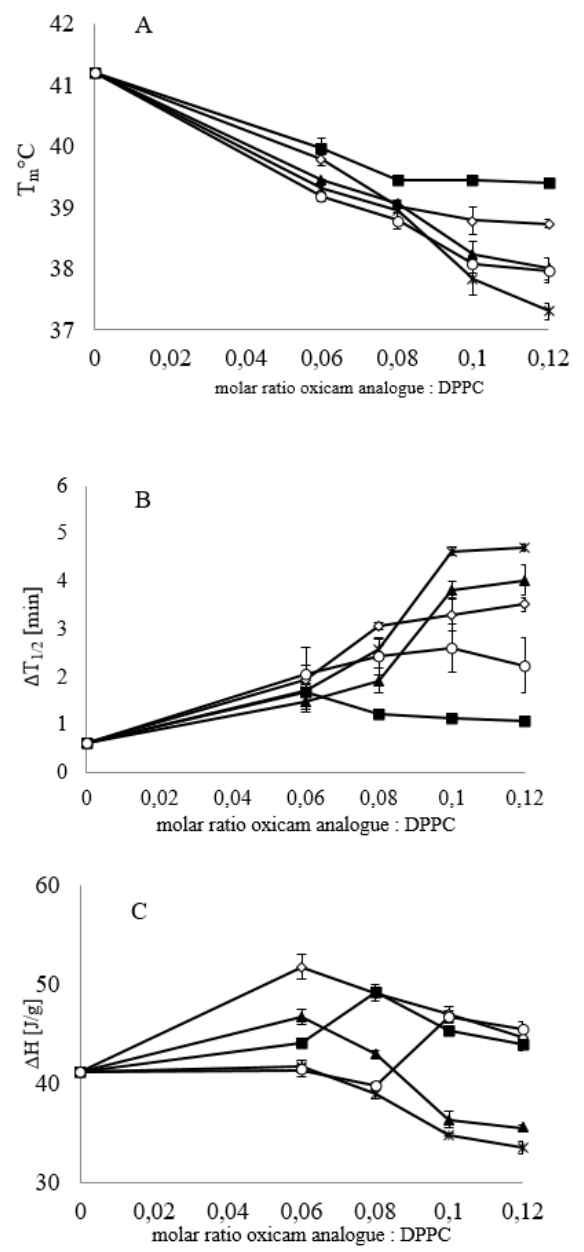

Figure 4. Influence of PR14 ( $)$ ), PR44 (目), PR45 (A), PR47 ( $\times$ ) and PR48 $(O)$ on the parameters of DPPC main phase transition: temperature (A), peak half-height width (B) and enthalpy change (C).

Bars represent standard deviations of eight measurements, where no error bars are shown, they were smaller than the symbols representing results.

PR44, PR45, PR47 and PR48 are shown in Figes. 4A$C$, respectively. All examined compounds decreased the main transition temperature $T_{m}$ of DPPC in a concentration-dependent manner (see Fig. 4A).

Newly synthesized oxicam derivatives exerted a markedly greater effect on thermotropic properties of DPPC multilamellar structures than piroxicam. The addition of studied compounds to phospholipid also caused broadening of the transition peaks which was visible as an increase of transition half-height width (Fig. 4B).

This process is accompanied by shifting of phase transition temperature $T_{\mathrm{m}}$ towards lower values and this shift is also dependent on the concentration of the studied compounds. Phase transition profiles were most effectively broadened by PR47.

Figure 4C shows the influence of the studied compounds on the enthalpy $(\Delta \mathrm{H})$ of DPPC main phase transition. PR47 decreased the transition enthalpy in a concentration-dependent manner to the greatest extent among all of the compounds examined.

In case of parameter changes of DPPC gel-liquid crystalline phase transition studied here, the most pronounced effects were found in the presence of compounds PR47 and PR45. In DSC studies PR44 appeared to be the least effective piroxicam derivative in the group of five studied compounds.

\section{Fluorescence spectroscopy}

To further study the effects of the new oxicams analogues on phospholipid bilayers two fluorescent probes localized in different membrane segments were applied. Laurdan and Prodan both possess the same fluorophore connected to an alkyl chain of different length (3 carbon atoms in Prodan molecule and 12 of Laurdan). Therefore Prodan molecules locate closer to the hydrophilic surface of a bilayer (Krasnowska et al., 1998) than Laurdan which flouorophore is located closer to the phospholipid glycerol groups (Bagatolli et al., 1999). All examined compounds caused quenching of both fluorescent probes in a concentration-dependant manner (see Fig. 5). The newly synthesized oxicams derivatives had a more pronounced effect on fluorescence quenching than piroxicam.

For all of the studied oxicams analogues quenching of Prodan fluorescence (open symbols) was significantly stronger than quenching of Laurdan emission (full symbols). According to the standard interpretation of fluorescence quenching proposed by Joseph Lakowicz if the molecular location of fluorescent probe within the lipid bilayer is known, quenching studies can be used to reveal the location of quenchers in membrane (Lakowicz, 2006).

The results of our fluorescence quenching studies suggest that in DPPC model membranes the oxicam derivatives are located in the region closer to the surface of the membrane where fluorescence probe Prodan is located. It was also found, that two out of five compounds under consideration, PR45 and PR47 (Fig. 5) quenched the fluorescence of both fluorescent probes most strongly.

The experiments carried out by fluorescence spectroscopy have shown that the presence of a two-carbon aliphatic linker with a carbonyl group between 4-[(3-trifluoromethyl)phenyl]piperazine substituent and 1,2-benzothiazine ring as well as trifluoromethyl substituent that occurs in compounds PR45 and PR47, seems to increase the ability of oxicams derivatives to quench the fluorescence of both applied probes.

\section{DISCUSSION}

The results obtained by both applied experimental techniques, differential scanning calorimetry and fluorescence spectroscopy have shown that the new oxicam analogues interact with model lipid membranes applied in these studies. All of the new oxicams analogues studied here abolished DPPC pretransition. These compounds were able to decrease the temperature of main phase transition and to influence enthalpy of the transition. They also increased half-height of the transition peaks.

Comparing the magnitude of changes induced by the studied analogues of oxicam in thermotropic properties of DPPC bilayers with their ability to quench Laurdan and Prodan fluorescence the following order was observed: PR47 $>$ PR 45 $>$ PR 48 $>$ PR14 $>$ PR 44 .

However, in case of two studied derivatives their ability to quench Laurdan fluorescence followed another order, i.e. P14>P48. The presence of a two-carbon aliphatic linker with a carbonyl group (PR14, PR45, PR47) in position 2 of the 1,2-benzothiazine ring (instead of a three-carbon chain in the same position of a compound scaffold - PR44, PR48) together with a trifluoromethyl 

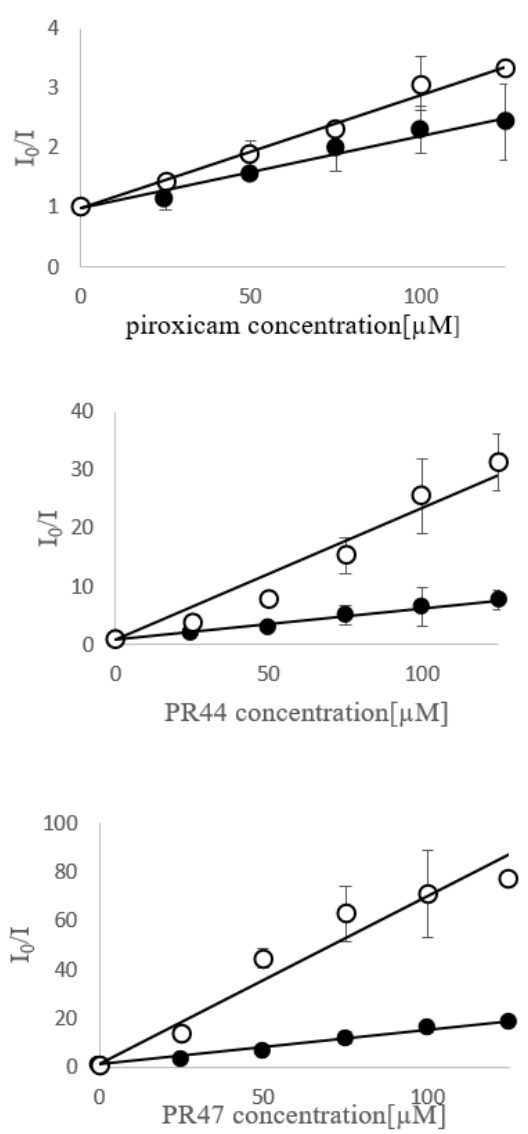
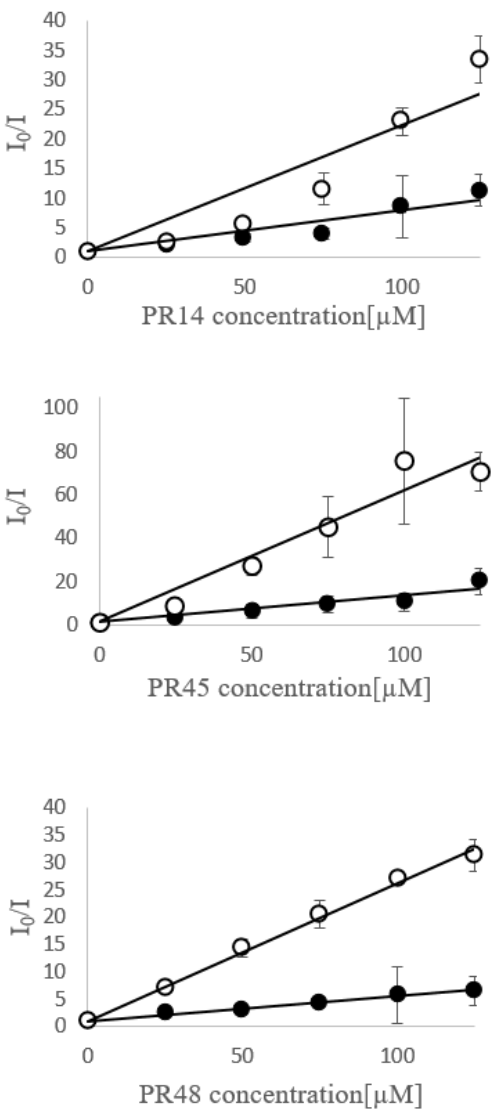

Figure 5. Stern-Volmer plots for quenching of Prodan (open symbols) and Laurdan (full symbols) fluorescence by piroxicam, PR14, PR44, PR45, PR47, PR48 in DPPC liposomes.

Bars represent standard deviations of three independent experiments, where no error bars are shown, they were smaller than the symbols representing results.

substituent in the benzene ring of phenyl-piperazine moiety (PR47 and PR45) appears to be crucial for model membrane perturbing potency of the studied derivatives. On the contrary, the substitution of the benzene ring by halogen substituents ( $\mathrm{Cl}$ or $\mathrm{Br})$ in position 3 of the 1,2-benzothiazine ring has little or no influence on the potency to perturb DPPC bilayers structure by these derivatives. No substituent in the benzene ring of 4-phenylpiperazine moiety (PR44, PR14) appears to be characteristic for compounds that perturb only polar head and in small extent acyl chain regions of lipid membranes.

\section{CONCLUSIONS}

As it was demonstrated in our calorimetric and spectroscopic studies, the greatest influence on thermotropic properties of DPPC membrane and on the efficiency of quenching of Laurdan and Prodan fluorescence was exerted by a PR47 derivative which contains in its structure a two-carbon aliphatic linker with a carbonyl group between 4-[(3- trifluoromethyl)phenyl]piperazine substituent and 1,2-benzothiazine ring as well as bromine and trifluoromethyl substituents.

In the present work we have used differential scanning calorimetry and fluorescence spectroscopy to study the interactions of new five oxicam derivatives with lipid bilayers. We have shown that these interactions indicate dependence on the chemical structure of individual compounds. However, the importance of the interactions of oxicam derivatives with lipids for their impact on different cellular pathways is far from being recognized. In the next step of the research we plan to study an ability of the new oxicam derivatives to inhibit transport activity of ABC multidrug transporters which are mostly responsible for anticancer drug resistance. Furthermore, the results of this study indicate that this area of research would be advanced by examination at a molecular level.

\section{Conflicts of interest}

The authors hereby declare that there are no conflicts of interest.

\section{Acknowledgments of Finanacial Support}

This work was financed by the Ministry of Science and Higher Education funds for Wroclaw Medical University, project No ST-D070.17.026.

\section{REFERENCES}

Bagatolli LA, Parasassi T, Fidelio GD, Gratton E (1999) A model for the interaction of 6-lauroyl-2-(N,N-dimethylamino)naphthalene with lipid environments: implications for spectral properties. Photochem Photobiol 70: 557-564

Chakraborty H, Chakraborty PK, Raha S, Mandal PC, Sarkar M (2007) Interaction of piroxicam with mitochondrial membrane and cytochrome c. Biochim Biophys Acta 1768: 1138-1145. doi: 10.1016/j. bbamem.2007.01.004

de Groot DJA, de Vries EGE, Groen HJM, de Jong S (2007) Non-steroidal anti-inflammatory drugs to potentiate chemotherapy effects: 
from lab to clinic. Crit Rev Oncol Hematol 61: 52-69. doi: 10.1016/j. critrevonc.2006.07.001

Dixon DA, Blanco FF, Bruno A, Patrignani P (2013) Mechanistic aspects of cox-2 expression in colorectal neoplasia. Recent Results Cancer Res 191: 7-37. doi:10.1007/978-3-642-30331-9_2

Ghosh N, Chaki R, Mandal V, Mandal SC (2010) COX-2 as a target for cancer chemotherapy. Pharmacol Rep 62: 233-244

Jain KJ Wu NM (1977) Effect of small molecules on the dipalmitoyl lecithin liposomal bilayer: phase transition in lipid bilayer. $J \mathrm{Mem}$ brane Biol 34: 157-201

Krasnowska EK, Gratton E, Parasassi T (1998) Prodan as a membrane surface fluorescence probe: partitioning between water and phospholipid phases. Biophys J 74: 1984-1993. doi: 10.1016/S00063495(98)77905-6

Krzyżak E, Szczęśniak-Sięga B, Malinka W (2014) Synthesis and thermal behaviour of new benzo-1,2-thiazine long-chain aryl-piperazine derivatives. J Thermal Analysis Calorimetry 115: 793-802. doi: 10.1007/ s10973-013-3185-1

Kyrikou I, Hadjikakou SK, Kovala-Demertzi D, Viras K, Mavromoustakos T (2004) Effects of non-steroid anti-inflammatory drugs in membrane bilayers. Chem Phys Lipids 132: 157-169. doi: 10.1016/j. chemphyslip.2004.06.005

Lakowicz JR (2006) Principles of Fluorescence Spectroscopy. 3rd edn, Springer. Heidelberg, New York. ISBN 978-0-387-46312-4

Lichtenberger LM, Zhou Y, Jayaraman V, Doyen JR, O’Neil RG, Dial EJ, Volk DE, Gorenstein DG, Boggara MB, Krishnamoorti R (2012) Insight into NSAID-induced membrane alterations, pathogenesis and therapeutics: characterization of interaction of NSAIDs with phosphatidylcholine. Biochim Biophys Acta 1821: 994-1002. doi: 994-1002. 10.1016/j.bbalip.2012.04.002.

Lúcio M, Lima JL, Reis S (2010) Drug-membrane interactions: significance for medicinal chemistry. Curr Med Chem 17: 1795-1809. doi: 10.2174/092986710791111233

Maniewska J, Szczęśniak-Sięga B, Poła A, Środa-Pomianek K, Malinka W, Michalak K (2014) The interaction of new piroxicam analogues with lipid bilayers - a calorimetric and fluorescence spectroscopic study. Acta Poloniae Pharmacentica - Drug Res 71: 1004-1012

Mbonye UR, Wada M, Rieke CJ, Tang HY, Dewitt DL, Smith WL (2006) The 19-amino acid cassette of cyclooxygenase-2 mediates entry of the protein into the endoplasmic reticulum-associated degradation system. J Biol Chem 281: 35770-35778. doi: 10.1074/jbc. M608281200
Nunes C, Brezesinski G, Pereira-Leite C, Lima JL, Reis S, Lúcio M (2011) NSAIDs interactions with membranes: a biophysical approach. Langmuir 27: 10847-10858. doi: 10.1021/la201600y

Park JH, McMillan DC, Horgan PG, Roxburgh CS (2014) The impact of anti-inflammatory agents on the outcome of patients with colorectal cancer. Cancer Treat Rev 40: 68-77. doi: 10.1016/j. ctrv.2013.05.006

Peetla C, Stine A, Labhasetwar V (2009) Biophysical interactions with model lipid membranes: applications in drug discovery and drug delivery. Mol Pharm 6: 1264-1275. doi: 10.1021/mp9000662.

Peetla C, Vijayaraghavalu S, Labhasetwar V (2013) Biophysics of cell membrane lipids in cancer drug resistance: Implications for drug transport and drug delivery with nanoparticles Adv Drug Deliv Rev 65: 1686-1698 doi: 10.1016/j.addr.2013.09.004

Pereira-Leite C, Nunes C, Reis S (2013) Interaction of nonsteroidal anti-inflammatory drugs with membranes: in vitro assessment and relevance for their biological actions. Prog Lipid Res 52: 571-584. doi: 10.1016/j.plipres.2013.08.003

Rizzo MT (2011) Cyclooxygenase-2 in oncogenesis. Clin Chim Acta 412: 671-687. doi: 10.1016/j.cca.2010.12.026

Seddon AM, Casey D, Law RV, Gee A, Templer RH, Ces O (2009) Drug interactions with lipid membranes. Chem Soc Rev 38: 25092519. doi: 10.1039/b813853m

Środa-Pomianek K, Wesołowska O, Szczęśniak-Sięga B, Puła B, Dziegiel P, Maniewska J, Palko-Łabuz A, Michalak K (2015) Effect of new oxicam derivatives on efflux pumps overexpressed in resistant a human colorectal adenocarcinoma cell line. Anticancer Res 35: 2835-2840

Wang D, Dubois RN (2010) Eicosanoids and cancer. Nat Rev Cancer 10: 181-193. doi: $10.1038 / \operatorname{nrc} 2809$

Wang D, Dubois RN (2010) The role of COX-2 in intestinal inflammation and colorectal cancer. Oncogene 29: 781-788. doi: 10.1038/ onc. 2009.421

Zhou Y, Hancock JF, Lichtenberger LM (2010) The nonsteroidal anti-inflammatory drug indomethacin induces heterogeneity in lipid membranes: potential implication for its diverse biological action. PLoS One 5: e8811

Xu S, Rouzer CA, Marnett LJ (2014) Oxicams, a class of nonsteroidal anti-inflammatory drugs and beyond. IUBMB Life 66: 803-811. doi: 10.1002/iub.1334 